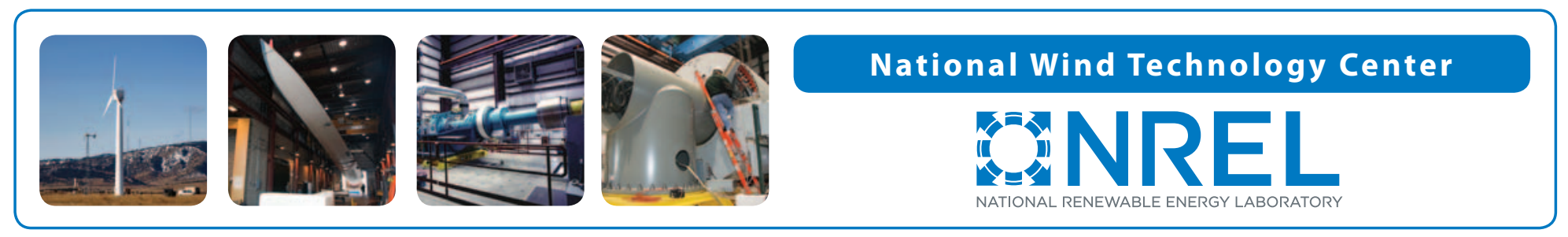

\title{
225-kW Dynamometer for Testing Small Wind Turbine Components
}

The public's concern over the cost and reliability of small wind turbines continues to be a barrier to the deployment of wind energy in the marketplace. A marketing advantage exists for manufacturers who can provide test results that prove the reliability of their turbine designs. This capability exists at the National Renewable Energy Laboratory's (NREL's) National Wind Technology Center (NWTC) near Boulder, Colorado .

NREL's 225-kW dynamometer tests a variety of components and subsystems, including generators, gearboxes, mechanical or electro-dynamic brakes, power electronics, control systems, and software.

Manufacturer's test objectives might include performance, system integration (generator, power electronics, and grid), software development, or accelerated life testing. NREL is actively seeking industry partners to utilize this facility and advance the technology for small, distributed wind turbines.

\section{Test Capabilities}

The 225-kW dynamometer can be used in a wide range of technology testing and development activities focusing on drive train components, power electronics, and controls used in small wind turbines. These include:

Generator/Alternator Testing

- Efficiency

- Cogging torque

- Equivalent circuit parameters

- Thermal characteristics

- Vibration

- Defect testing (infant mortality)

- Insulation life testing

Gearbox Testing

- Efficiency

- Thermal characteristics

- Lubrication flow

- Tooth contact patterns

- Vibration

- Endurance or fatigue

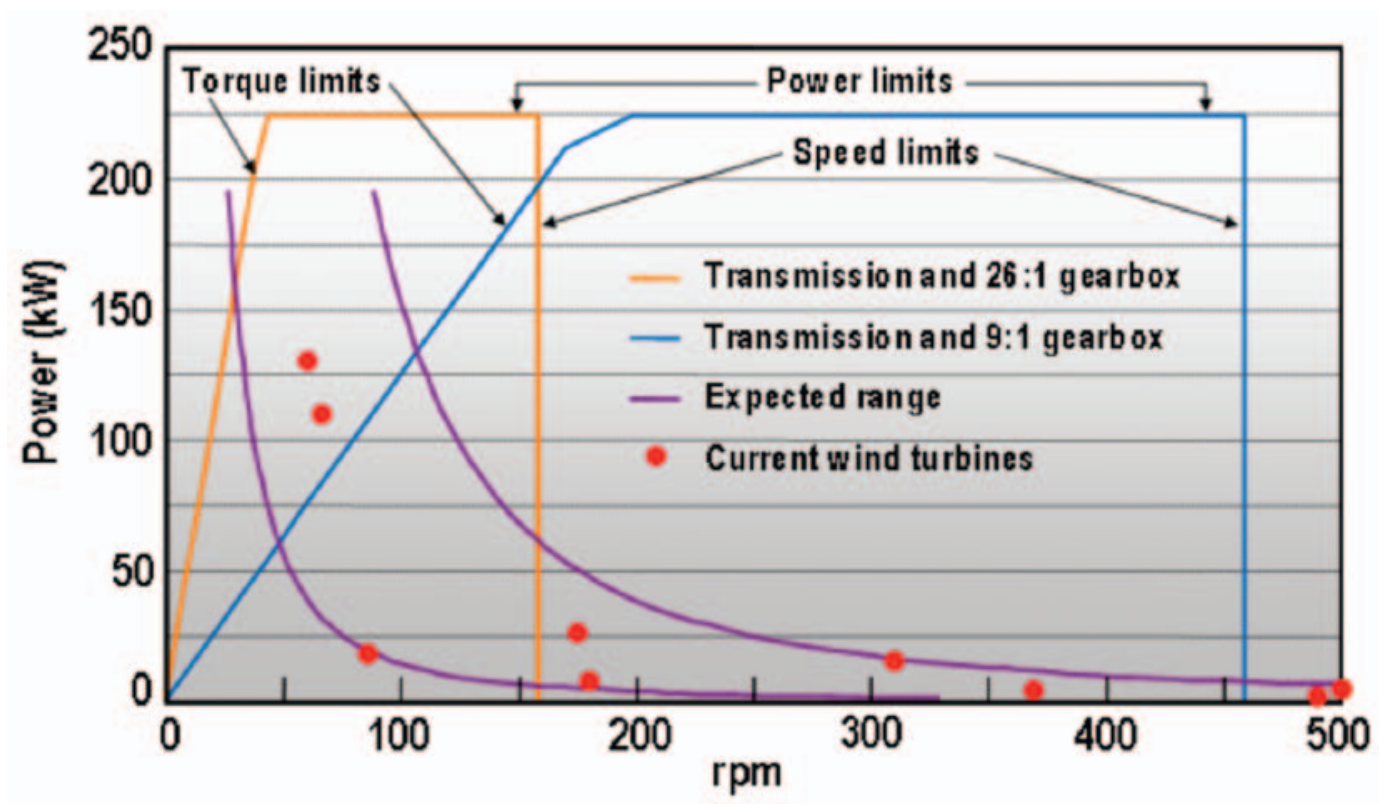

Operating Envelope for the NWTC 225-kW Dynamometer
Power Electronics Testing

- Efficiency

- Thermal characteristics

- Control and stability

- Power quality

- Defect testing (infant mortality)

- Control systems and software testing

- System integration (generator/power electronics/grid)

- Software development and testing

\section{Operating Envelope}

The NWTC 225-kW dynamometer tests small wind turbine components from the smallest turbines to turbines with nearly $200-\mathrm{kW}$ ratings. Some headroom between the component rating and the dynamometer rating is typically needed to adequately cover over-speed and over-torque conditions that turbine components encounter in real applications. Maximum available shaft speed is 4,140 revolutions per minute (rpm) and the maximum available shaft torque is 37,000 foot-pounds (ft-lb) or 51,000 Newton meters ( $\mathrm{Nm}$ ). The operating envelope depicted in the figure also shows the range of expected values of power vs. rpm for typical small wind turbines. 


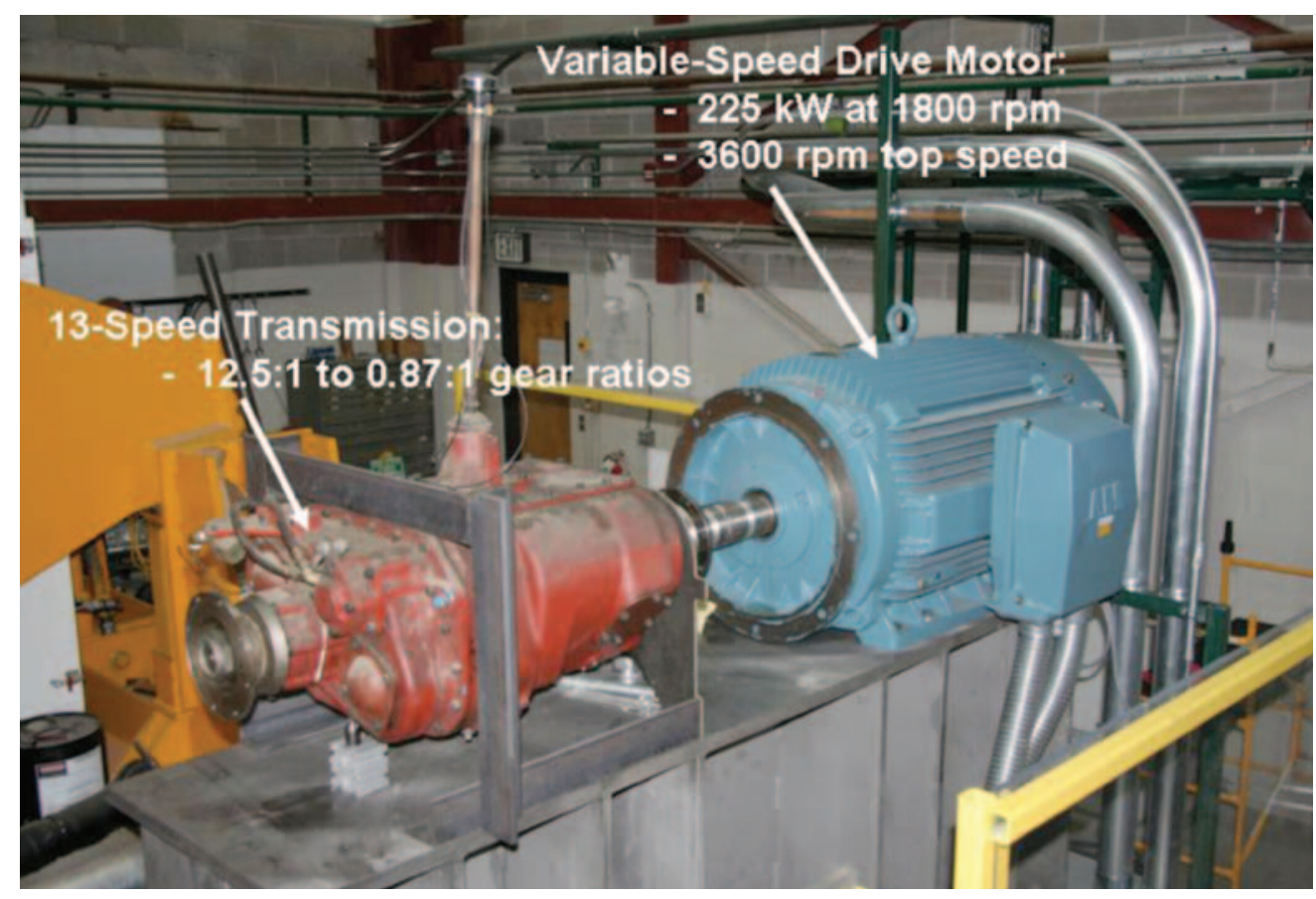

225-kW Dynamometer. PIX \#14739.

\section{Electric Loads}

Three types of electric loads are available for units under test on the dynamometer. The first is single-phase service at 120/240 volts alternating current (VAC), $60 \mathrm{Hertz}(\mathrm{Hz})$, with up to 50 kilovoltampere (kVA) capacity. This load simulates the typical 100- or 200-ampere (A) utility service available to most homes, small farms, and small businesses. The second load is three-phase service at $480 \mathrm{VAC}, 60 \mathrm{~Hz}$, with up to $250 \mathrm{kVA}$ capacity. This simulates utility service for farms and businesses that have larger power requirements, up to $250 \mathrm{~kW}$. Other service voltages as well as $50 \mathrm{~Hz}$ operation are possible but will require enhancements to the facility. For testing off-grid systems designed to charge batteries, the dynamometer includes battery bank simulation via a voltage-controlled direct current (DC) bus with capacity up to $20 \mathrm{kVA}$ and voltages up to 216 volts DC.

\section{Dyno Components}

The drive system for the dynamometer consists of a drive motor coupled to one or more speed-reducing gear boxes selected to deliver the requisite torque and shaft speed for a given test program. These components are installed on concrete and steel pedestals with a drive shaft extending over a rigid steel table as shown in the photo above. This table is on jack screws such that its height can be changed to allow alignment of various test article input shafts with the dynamometer drive shaft. At its lowest available height, the table is about $5 \mathrm{ft}$ or 1.5 meters $(\mathrm{m})$ below the dynamometer drive shaft, providing room for installation of test articles with diameters up to about 8-10 ft (2.4-3.0 m).
The dynamometer drive motor is a 225-kW (300-horsepower [hp]) rated, variable-speed, induction motor, with a matched variable-speed drive and harmonic filter. The motor reaches rated power at 1,800 rpm and has a top speed of $3,600 \mathrm{rpm}$.

Three speed-reducing gearboxes are available for the dynamometer. The first, coupled to the drive motor, is a 13-speed transmission with gear ratios ranging from 12.5:1 up to an overdrive gear at $0.87: 1$. This transmission will be coupled directly to the unit under test or to one of two fixed speed gear boxes to reduce shaft speed and increase torque. These gear boxes have ratios of 9:1 and 26:1. Gearbox specifications are shown in Table 1.

Table 1. NWTC 225-kW Dynamometer Gearbox Specifications

\begin{tabular}{|c|c|c|c|}
\hline Device & Brand & Gear Ratios & Torque Limit \\
\hline Transmission & Fuller & $\begin{array}{c}13 \text { ratios } 12.5: 1- \\
0.87: 1\end{array}$ & $\begin{array}{l}1,250 \mathrm{ft}-\mathrm{lb} \\
1,700 \mathrm{Nm}\end{array}$ \\
\hline Fixed-Ratio Gearbox & Byrne & $9: 1$ & $\begin{array}{l}8,750 \mathrm{ft}-\mathrm{lb} \\
(11,900 \mathrm{Nm})\end{array}$ \\
\hline Fixed-Ratio Gearbox & Flender & $26: 1$ & $\begin{array}{l}37,600 \mathrm{ft}-\mathrm{lb} \\
(51,000 \mathrm{Nm})\end{array}$ \\
\hline
\end{tabular}

\section{Partnerships with NREL}

The NWTC is seeking opportunities to collaborate with industry partners in the use of the 225-kW dynamometer for small wind turbine technology development. For more information, contact:

Jim Johnson

National Wind Technology Center

National Renewable Energy Laboratory

1617 Cole Blvd., MS 3811

Golden, CO 80401

Jim.johnson@nrel.gov

303-384-6989

\section{National Renewable Energy Laboratory}

1617 Cole Boulevard, Golden, Colorado 80401 • 303-275-3000 • www.nrel.gov

NREL is a national laboratory of the U.S. Department of Energy

Office of Energy Efficiency and Renewable Energy

Operated by the Alliance for Sustainable Energy, LLC

NREL/FS-500-48536 • June 2010 